\title{
Multi Response Optimization of ECDM Process Parameters for Machining of Microchannel in Silica Glass Using Taguchi-GRA Technique
}

Sadashiv Bellubbi ( $\square$ bellubbisadashiv@gmail.com )

Alva's Institute of Engineering and Technology https://orcid.org/0000-0003-4095-9497

\section{Sathisha Nanjundaswamy}

YIT: Yenepoya Institute of Technology

Bijan Mallick

Techno International New Town

\section{Original Research}

Keywords: ECDM, silica glass, SOD, electrolyte concentration, grey relational analysis (GRA), MRR, overcut, microchannel

Posted Date: February 10th, 2021

DOl: https://doi.org/10.21203/rs.3.rs-177794/v1

License: (c) (i) This work is licensed under a Creative Commons Attribution 4.0 International License. Read Full License

Version of Record: A version of this preprint was published at Silicon on June 22nd, 2021. See the published version at https://doi.org/10.1007/s12633-021-01167-4. 


\title{
Multi Response Optimization of ECDM Process Parameters for Machining of Microchannel in Silica Glass Using Taguchi-GRA Technique
}

\author{
Sadashiv Bellubbi ${ }^{12^{*}}$, Sathisha Nanjundaswamy ${ }^{3}$, Bijan Mallick ${ }^{4}$ \\ ${ }^{1}$ Department of Mechanical Engineering, Alva's Institute of Engineering and Technology, Moodbidri, \\ Mangaluru, Karnataka, India-574225 \\ ${ }^{2}$ Research scholar, Visvesvaraya Technological University, Belagavi, Karnataka, INDIA \\ ${ }^{3}$ Department of Mechanical Engineering, Yenepoya Institute of Technology, Moodbidri, Mangaluru, \\ Karnataka, India-574225 \\ ${ }^{4}$ Department of Mechanical Engineering, Techno International Batanagar, West Bengal, India \\ *Corresponding Author: bellubbisadashiv@gmail.com
}

\begin{abstract}
In this work, machining of microchannel in silica glass was successfully carried out using electro chemical discharge machining (ECDM) process. The experiments were planned according to $\mathrm{L}_{27}$ orthogonal array with applied voltage, stand-off distance (SOD), electrolyte concentration, pulse frequency and pulse-on-time $\left(\mathrm{T}_{\mathrm{ON}}\right)$ as control factors. The material removal rate (MRR), overcut (OC) and tool wear rate (TWR) were considered as response characteristics. In this study the effects of control parameters on MRR, OC and TWR have been investigated. The multi-objective optimization of ECDM was carried out through grey relational analysis (GRA) method. Optimal combination of process parameters achieved from GRA was $45 \mathrm{~V}$ applied voltage, $25 \mathrm{wt}$.\% electrolyte concentration, $1.5 \mathrm{~mm} \mathrm{SOD}, 400 \mathrm{~Hz}$ pulse frequency and $45 \mu \mathrm{s} \mathrm{T}_{\mathrm{ON}}$. ANOVA for GRG study revealed that the applied voltage $(70.33 \%)$ was most significant factor affecting output responses followed by electrolyte concentration $(11.69 \%)$, pulse frequency $(4.98 \%)$ and SOD $(4.13 \%)$. Furthermore, the regression equations were formulated for the optimum combination to predict the collaboration and higher-order effects of the control parameters. In addition confirmation test was conducted for the optimal setting of process parameters and the comparison of experimental results exhibited a good agreement with predicted values. The microstructural observation of machined surface for the optimum combination was carried out.
\end{abstract}

Keywords: ECDM, silica glass, SOD, electrolyte concentration, grey relational analysis (GRA), MRR, overcut, microchannel. 


\section{Introduction}

Nowadays, silica glass plays a significant role in potential areas like medical, MEMS, windows, optical lenses, crucibles, metrological instruments etc., attributed to its relatively higher thermal shock resistance and low coefficient of thermal expansion [1]. Howbeit, this is hard to machine material owing to its properties like high hardness and brittleness [2] and therefore non-traditional machining methods are called for machining these glasses. Several works in this regard have been reported for machining these glasses through USM, LBM, AJM, EDM, ECM, CHM, ECDM and WJM etc. Presently electro chemical discharge machining (ECDM) process is emerging as a cost effective substitute for ultrasonic machining, laser ablation and wet chemical etching to produce micro features in nonconductive materials such as pyrex glass, borosilicate glass, silica glass, silicon wafers, quartz and ceramics [3]. ECDM process is a hybrid process which combines the features of ECM and EDM to produce micro-features like deep holes, narrow channels and small lots in nonconductive materials [3-4]. Chemical and thermal phenomena are the primary mechanisms of this process to erode the material from the work material [5] thereby achieving the advantages of both; electrochemical dissolution as well as electric-discharge erosion from the work material [6].

In the past, several studies have been conducted to investigate the effects of the ECDM process parameters such as pulse frequency, applied voltage, current density, electrolyte concentration, anode to cathode distance, tool feed rate, pulse-on-time, duty cycle, stand-offdistance, different electrolytes, various tool materials etc. The machining of borosilicate glass[4,7], alumina substrate[3], silica glass [1,8], pyrex glass and soda lime glass [9-11], fused silica and quartz [3], carbon fiber reinforced polymer (CFRP) [12] on hole geometry, overcut, HAZ, MRR, machining depth, circularity error, surface roughness, tool wear rate etc. have been investigated.

Optimization of control parameters plays a significant role and assists to identify the range of most effective parameter that controls the machining performance in ECDM. Several optimization methods were suggested to establish mathematical formulation between control parameters and response variables in ECDM process to produce micro-channels, micro-holes, texturing and grooves. Taguchi-GRA is one of the attractive optimization techniques employed by many investigators to establish a control over the uncertainty and optimize several responses in a process [13-14]. Taguchi-GRA is extensively employed for evaluating the degree of relationship between arrangements by grey relational grade (GRG). Several researchers have recently used GRA technique to optimize the combination of different 
process parameters on sodalime glass [15], quartz glass [16], fiber glass reinforced [17], borosilicate glass [18-19], CFRP composites[12], silica (quartz) material[20], silicon wafer [21]. Works reported hitherto prove the effectiveness of Taguchi-GRA for optimizing ECDM process parameters; nevertheless the available literature reveals the scarcity of published works reported on micromachining of silica glass and relevant multi response optimization through GRA. In this work, the influence of control factors; applied voltage, pulse frequency, pulse-on-time, stand-off-distance and electrolyte concentration on response variables; MRR, OC and TWR have been investigated. Furthermore, multi response optimization of ECDM of silica glass through Taguchi-GRA has been proposed and the significance of process parameters was determined through ANOVA. Subsequently, the confirmation test was carried out by considering the optimal combination of process parameters.

\section{Experimental work}

Recent developments in ECDM process comprises with micro-machining of ceramics, glass, composites, silicon wafer and quartz with enhanced output responses [4]. The performance of ECDM process in terms of width of cut, surface roughness, machining depth, TWR, MRR, heat affected zone, recast layer is mainly dependent on various factors like SOD, voltage, current density, electrolyte concentration, auxiliary electrode material, tool materials, electrolyte and pulse factors of supply.

\subsection{Materials and Methods}

In this research, silica glass of size $75 \times 26 \times 1.2 \mathrm{~mm}^{3}$ was used as the work material for experimentation. Table 1 presents the physical properties of silica glass used in the present work. The main composition of silica glass is $\mathrm{SiO}_{2}$ that increases the resistance to thermal shocks[22]. The required ECDM facility for the experimentation was developed as shown in Fig. 1(a) which consists of power regulated supply, tool holder equipped with 3-axis movement, fixture for holding workpiece, electrodes and electrolyte container. The tool head movement was controlled by GRBL software. A Tungsten carbide tool of $250 \mu \mathrm{m}$ diameter was considered as cathode, graphite plate of $300 \times 200 \mathrm{~mm}$ was used as anode and $\mathrm{NaOH}$ solution with varying concentrations was employed as electrolyte solution. Figure 1(b) shows typical photograph of silica glass with micro machined groove. 


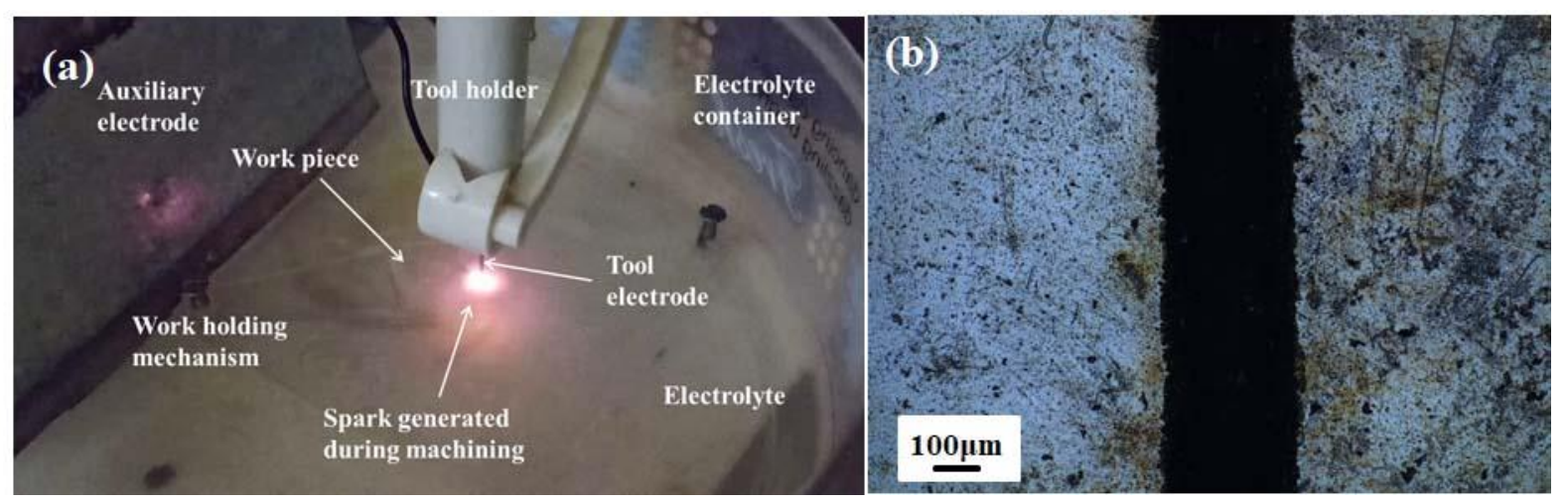

Fig. 1 Images of (a) ECDM (b) Optical image of Silica glass with micro-channel

Table 1 Properties of silica glass [8]

\begin{tabular}{lc}
\hline \multicolumn{1}{c}{ Properties } & Value \\
\hline Tensile strength $\left(\mathrm{N} / \mathrm{m}^{2}\right)$ & $50 \times 10^{6}$ \\
Thermal conductivity $(\mathrm{W} / \mathrm{m}-\mathrm{K})$ & 1.2 \\
Elastic modulus $\left(\mathrm{N} / \mathrm{m}^{2}\right)$ & $72 \times 10^{9}$ \\
Density $\left(\mathrm{kg} / \mathrm{m}^{3}\right)$ & $2.519 \times 10^{3}$ \\
Thermal expansion $\left(\mathrm{K}^{-1}\right)$ & $0.54 \times 10^{-6}$ \\
Melting temperature $\left({ }^{\circ} \mathrm{C}\right)$ & 1400 \\
Refractive index & 1.518 \\
\hline
\end{tabular}

The machining parameters during pilot experiments were selected based on literature review and initial experiments were conducted by one time approach. After performing the pilot experiments, it was noticed that the viable range of applied voltage was $45-55 \mathrm{~V}$, the electrolyte concentration range $10-25 \mathrm{wt} \%$, the SOD $0.5-1.5 \mathrm{~mm}$, the pulse frequency 200 $400 \mathrm{~Hz}$ and the pulse on time $45-55 \mu$ s. The parameter design in present work is based on three levels for each machining parameter as shown in Table 2. Stand-off distance was controlled by inserting slip gauges between the work material and tool-tip. Inter-electrode-gap and machining time were kept constant as $40 \mathrm{~mm}$ and 20 minutes respectively for all trials.

The most prominent output responses were identified and selected as MRR, OC and tool wear rate (TWR). MRR and TWR were determined in terms of material eroded per unit time. The samples and tools in each trial were precisely weighed before and after machining using a digital electronic balance (Make: Mettler Toledo, India) with $0.01 \mathrm{mg}$ resolution. The overcut was measured using Leica microscope at various locations throughout the length of microchannel and the average values have been considered. Machined surfaces were exposed 
to micrographic observations through scanning electron microscope; SEM (Model: JEO JSM-638OLA from JEOL, Japan).

Table 2 Machining parameters and their levels

\begin{tabular}{lccccc}
\hline Parameters & Unit & Factor & Level 1 & Level 2 & Level 3 \\
\hline Applied voltage & $\mathrm{V}$ & $\mathrm{A}$ & 45 & 50 & 55 \\
Electrolyte concentration & $\mathrm{Wt} . \%$ & $\mathrm{~B}$ & 10 & 17.5 & 25 \\
Stand-off-distance & $\mathrm{mm}$ & $\mathrm{C}$ & 0.5 & 1.0 & 1.5 \\
Pulse frequency & $\mathrm{Hz}$ & $\mathrm{D}$ & 200 & 300 & 400 \\
Pulse-on-time & $\mu \mathrm{s}$ & $\mathrm{E}$ & 45 & 50 & 55 \\
\hline
\end{tabular}

\subsection{Working principle of ECDM process}

The ECDM setup comprises of a primary tool electrode as cathode and a secondary metallic sheet as auxiliary electrode (anode) separated by an inter-electrode gap filled with electrolyte solution and regulated DC power supplied between both the electrodes.

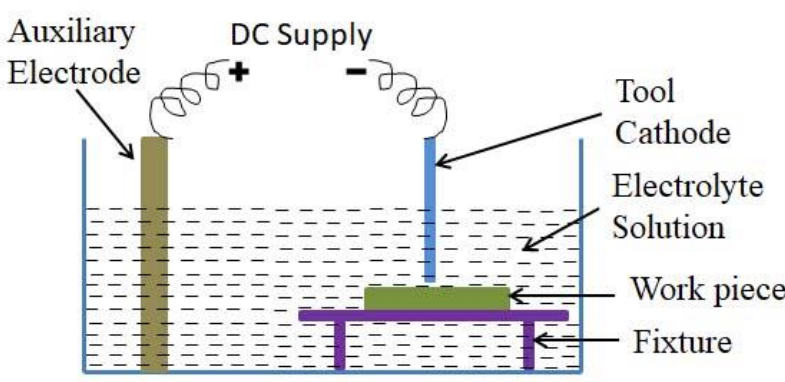

(a)

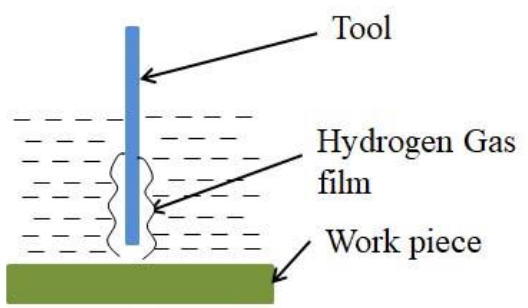

(c)

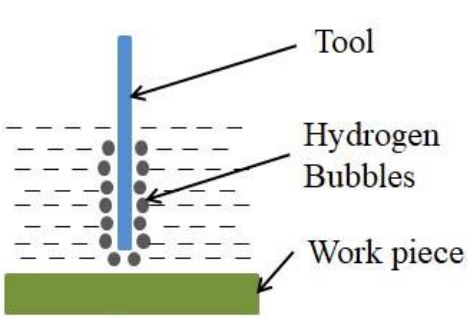

(b)

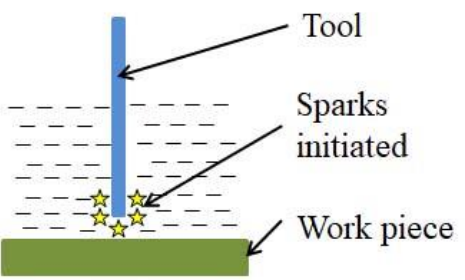

(d)

Fig. 2 (a) Schematic view of ECDM setup (b) Hydrogen bubbles formation (c) Hydrogen gas film formation (d) Spark initiation

The cathode tool is relatively much smaller than the auxiliary electrode [23]. The work sample is placed below the tool and submerged in electrolyte solution as in Fig. 2(a). As the voltage is applied across the electrodes, the electrochemical reactions occur in the electrolyte solution [12]. Continued voltage supply and high current density boosts the electro chemical reactions and results in the formation of hydrogen bubbles in the vicinity of the tool [24] (Fig. 
2(b)). The high density of hydrogen bubbles forms a casing around tool electrode (Fig. 2(c)). This casing behaves as dielectric between cathode tool and electrolyte solution, as the applied potential crosses the dielectric power of gas film, the spark is persuaded around tool electrode as shown in (Fig. 2(d)). Therefore, the work material beneath the tool electrode softens due to spark energy, chemical etching and thermal erosion. As a result spark discharges promise a sequence of micro erosions in the layer of work piece, so that micro quantities of material takes place from work material continuously [6-7].

\subsection{Genichi Taguchi method}

The Taguchi OA lessens the number of trials and hence, time and cost essential for the experimentation. Commonly, based on the process parameters and their levels, more number of trials needs to be conducted as per traditional strategy. The intention behind selection of Taguchi-OA is to afford for the optimum level of each parameter so as to decide the relative contribution of individual parameter using ANOVA [13,25]. The experimental design in the present work was planned using Minitab-17 software which resulted in 27 trials to be performed.

\subsection{Grey relational analysis (GRA)}

The GRA has provided the information that, any experimental analysis provides complete precise information called white; else the analysis contains lack of information named as black. For instance the analysis is combination of both, then it is called grey and such analysis is termed as grey relational analysis $[14,26]$. While optimizing through Taguchi's approach, single response function can be optimized, so that the obtained result gives better MRR, low OC and low TWR. Instead of having various optimized results, GRA provides single optimum combination of parameters for better MRR, OC and TWR. This technique involves normalization of the obtained results to find grey relational coefficients (GRCs) and then grey relational grades (GRGs) [27]. The combination of parameters with highest GRG is closest to optimum solution and considered as best possible setting of parameters. Furthermore, the ANOVA is executed to predict the optimum GRG. GRA have been employed by various researchers in their related field for multi-objective optimization of process parameters[28]. Figure 3 illustrates the steps involved in GRA. 


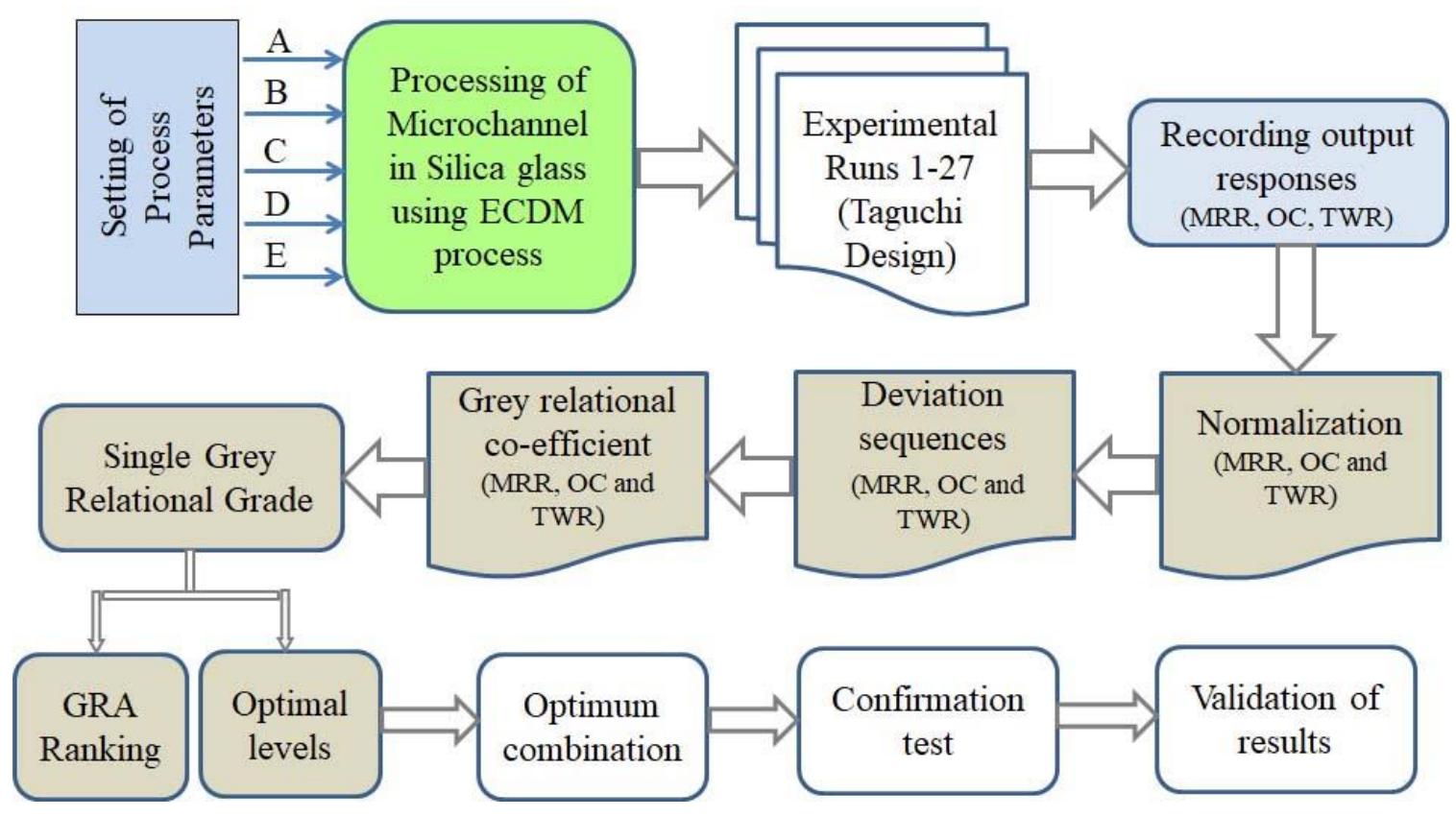

Fig. 3 Steps involved in GRA method

\section{Results and Discussion}

Experimentation carried out to study the influence of control factors on MRR, OC and TWR according to design matrix shown in Table 3. Further, ANOVA was performed to study the significance and individual contribution of each control factors towards MRR, OC and TWR as shown in Table 4. Consequently GRA has been performed to achieve the best possible combination of process parameters resulting in optimal setting followed by confirmation test to ensure the same.

\subsection{Influence of process parameters on response characteristics}

In general, any increment in voltage enhances in magnification of the coalescence of gas bubbles that boosts the intensity of spark over the work material. As a result, higher material removal takes place due to larger thermal energy input. An increase in electrolyte produces the $\mathrm{OH}$ ions which escalates its electrical conductivity. Due to the high melting point of the Tungsten Carbide tool, the amount of molten material removed on the tool is very low compared to the workpiece [24]. As SOD increases, the spark generation between tool and workpiece reduces hence every discharge removes very little amount of material from tool electrode and work sample [29]. Influence of process parameters was analyzed based on the results obtained in Table 3. Also ANOVA was performed to find contribution of individual parameters on responses as shown in Table 4. Accordingly in the following sections the effect of process parameters and their individual contributions on MRR, OC and TWR has been elucidated. 
Table $3 \mathrm{~L}_{27}$ orthogonal array layout with response variable

\begin{tabular}{|c|c|c|c|c|c|c|c|c|}
\hline \multirow{2}{*}{$\begin{array}{l}\text { Run } \\
\text { No. }\end{array}$} & \multicolumn{5}{|c|}{ Input parameters } & \multicolumn{3}{|c|}{ Output responses } \\
\hline & $\begin{array}{c}\text { Applied } \\
\text { Voltage (V) }\end{array}$ & $\begin{array}{c}\text { Electrolyte } \\
\text { Conc. (wt.\%) }\end{array}$ & $\begin{array}{l}\text { SOD } \\
(\mathrm{mm})\end{array}$ & $\begin{array}{c}\text { Pulse } \\
\text { frequency }(\mathrm{Hz})\end{array}$ & $\begin{array}{l}\text { Pulse-on } \\
\text { time }(\mu \mathrm{s})\end{array}$ & $\begin{array}{c}\text { MRR } \\
(\mathrm{mg} / \mathrm{hr})\end{array}$ & $\begin{array}{c}\mathrm{OC} \\
(\mu \mathrm{m})\end{array}$ & $\begin{array}{c}\text { TWR } \\
(\mathrm{mg} / \mathrm{hr})\end{array}$ \\
\hline 1 & 45 & 10 & 0.5 & 200 & 45 & 56.325 & 124.717 & 0.112 \\
\hline 2 & 45 & 10 & 0.5 & 200 & 50 & 57.305 & 128.644 & 0.116 \\
\hline 3 & 45 & 10 & 0.5 & 200 & 55 & 58.970 & 131.587 & 0.119 \\
\hline 4 & 45 & 17.5 & 1 & 300 & 45 & 58.420 & 130.119 & 0.117 \\
\hline 5 & 45 & 17.5 & 1 & 300 & 50 & 59.010 & 131.060 & 0.118 \\
\hline 6 & 45 & 17.5 & 1 & 300 & 55 & 62.370 & 139.432 & 0.126 \\
\hline 7 & 45 & 25 & 1.5 & 400 & 45 & 49.040 & 108.951 & 0.096 \\
\hline 8 & 45 & 25 & 1.5 & 400 & 50 & 51.820 & 114.960 & 0.102 \\
\hline 9 & 45 & 25 & 1.5 & 400 & 55 & 53.050 & 117.488 & 0.105 \\
\hline 10 & 50 & 10 & 1 & 400 & 45 & 69.860 & 155.694 & 0.142 \\
\hline 11 & 50 & 10 & 1 & 400 & 50 & 71.950 & 160.523 & 0.147 \\
\hline 12 & 50 & 10 & 1 & 400 & 55 & 74.010 & 165.235 & 0.152 \\
\hline 13 & 50 & 17.5 & 1.5 & 200 & 45 & 75.870 & 168.723 & 0.156 \\
\hline 14 & 50 & 17.5 & 1.5 & 200 & 50 & 76.765 & 170.835 & 0.158 \\
\hline 15 & 50 & 17.5 & 1.5 & 200 & 55 & 83.900 & 186.855 & 0.174 \\
\hline 16 & 50 & 25 & 0.5 & 300 & 45 & 100.190 & 220.300 & 0.207 \\
\hline 17 & 50 & 25 & 0.5 & 300 & 50 & 77.560 & 165.512 & 0.158 \\
\hline 18 & 50 & 25 & 0.5 & 300 & 55 & 84.940 & 189.467 & 0.176 \\
\hline 19 & 55 & 10 & 1.5 & 300 & 45 & 69.275 & 154.505 & 0.141 \\
\hline 20 & 55 & 10 & 1.5 & 300 & 50 & 75.910 & 168.810 & 0.156 \\
\hline 21 & 55 & 10 & 1.5 & 300 & 55 & 76.640 & 178.041 & 0.165 \\
\hline 22 & 55 & 17.5 & 0.5 & 400 & 45 & 81.250 & 181.024 & 0.168 \\
\hline 23 & 55 & 17.5 & 0.5 & 400 & 50 & 83.820 & 186.733 & 0.173 \\
\hline 24 & 55 & 17.5 & 0.5 & 400 & 55 & 86.715 & 193.222 & 0.180 \\
\hline 25 & 55 & 25 & 1 & 200 & 45 & 76.680 & 170.658 & 0.158 \\
\hline 26 & 55 & 25 & 1 & 200 & 50 & 82.765 & 184.313 & 0.171 \\
\hline 27 & 55 & 25 & 1 & 200 & 55 & 102.470 & 231.325 & 0.218 \\
\hline
\end{tabular}

\subsubsection{Effect of control factors on MRR}

It was noticed from Table 3 that, the MRR enhanced with increase in applied voltage. This is attributed to the formation of heavily crowded hydrogen bubbles along the edge of cathode tool. The coalescence of hydrogen bubbles promotes the occurrence of sparks which resulted 
in higher MRR. Likewise, the increase in concentration boosted the MRR. The high electrolyte concentration stimulates the kinetics of electrochemical reactions. As a result, the electrochemical reaction accelerates and leads to the increase in coalescence rate of hydrogen bubbles thereby producing more discharge energy in machining area. This high discharge produces melting and vaporizes work material. On the contrary, MRR decreases as SOD increases; this is because as the gap between tool and workpiece increases the kinetics of electrochemical reactions diminishes, resulting in decrease of sparking phenomenon. Further it was noticed that, with increase in pulse frequency, the length of the on-time reduces resulting in lower MRR. Whereas, shorter on-times erodes very little material and generate smaller craters [29]. These observations made are consistent with those investigated by other researchers $[4,12]$. From ANOVA study, it was noticed that applied voltage $(70.13 \%)$ is the mostly influencing factor affecting MRR. The SOD (6.19\%) and electrolyte concentration (5.90\%) marginally influences the MRR as in Table 4.

Table 4 Results of ANOVA for response characteristics

\begin{tabular}{clccccc}
\hline $\begin{array}{c}\text { Response } \\
\text { variable }\end{array}$ & \multicolumn{1}{c}{ Source } & DF & Seq SS & Adj MS & \% Contribution & Remarks \\
\hline \multirow{4}{*}{ Material } & Applied voltage (V) & 2 & 3575.2 & 1787.58 & 70.13 & Significant \\
Removal & Electrolyte Conc. (wt.\%) & 2 & 300.7 & 150.34 & 5.90 & Significant \\
Rate & Pulse frequency (Hz) & 2 & 315.5 & 157.73 & 6.19 & Significant \\
& Pulse on time (Hz) & 2 & 160.4 & 80.20 & 3.15 & Insignificant \\
& Residual Error & 16 & 588.4 & 36.77 & 3.10 & Insignificant \\
& Total & 26 & 5097.9 & & & \\
\hline \multirow{5}{*}{ Overcut } & Applied voltage (V) & 2 & 17945.8 & 8972.9 & 70.22 & Significant \\
& Electrolyte Conc. (wt.\%) & 2 & 1221.0 & 610.5 & 4.78 & Insignificant \\
& SOD (mm) & 2 & 1324.0 & 662.0 & 5.18 & Insignificant \\
& Pulse frequency (Hz) & 2 & 818.5 & 409.3 & 3.20 & Insignificant \\
& Pulse on time (Hz) & 2 & 1060.4 & 530.2 & 4.15 & Insignificant \\
& Residual Error & 16 & 3186.8 & 199.2 & & \\
& Total & 26 & 25556.4 & & & Significant \\
Tool wear & Applied voltage (V) & 2 & 0.0179 & 0.0089 & 70.44 & Insignificant \\
rate & Pulse frequency (Hz) & 2 & 0.0009 & 0.0004 & 3.39 & Insignificant \\
& Pulse on time (Hz) & 2 & 0.0010 & 0.0005 & 3.97 & Insignificant \\
& Residual Error & 16 & 0.0029 & 0.0002 & & \\
& Total & 26 & 0.0254 & & & \\
\hline
\end{tabular}




\subsubsection{Effect of control factors on overcut}

The overcut increases with rise in voltage supply and electrolyte concentration while it decreases with increase in SOD and pulse frequency. As the applied voltage increases the thickness of hydrogen gas envelope increases around the cathode due to thicker hydrogen bubbles [24]. Therefore, sparking at the sides of cathode electrode upholds overcut as shown in Fig. 4 which depicts the typical cases observed with smaller and larger overcuts. The increase in electrolyte increases stray sparking over vicinity of tool electrode which leads to overcut. During the pulse interval, the regulated power supply is cut off and the hydrogen bubble formation is ceased thereby momentary extinction of sparks occurs which leads in smaller overcut. By choosing high frequency pulse parameters and lesser duty ratios, the surface roughness and overcut of machined area can be reduced [29]. From Table 4, it was observed from ANOVA that the applied voltage (70.22\%) is the most significant factor influencing overcut, followed by the SOD (5.18\%) and the electrolyte concentration $(4.78 \%)$. In similar works, Garg et al. [12] reported that overcut rises with increase in voltage and concentration.
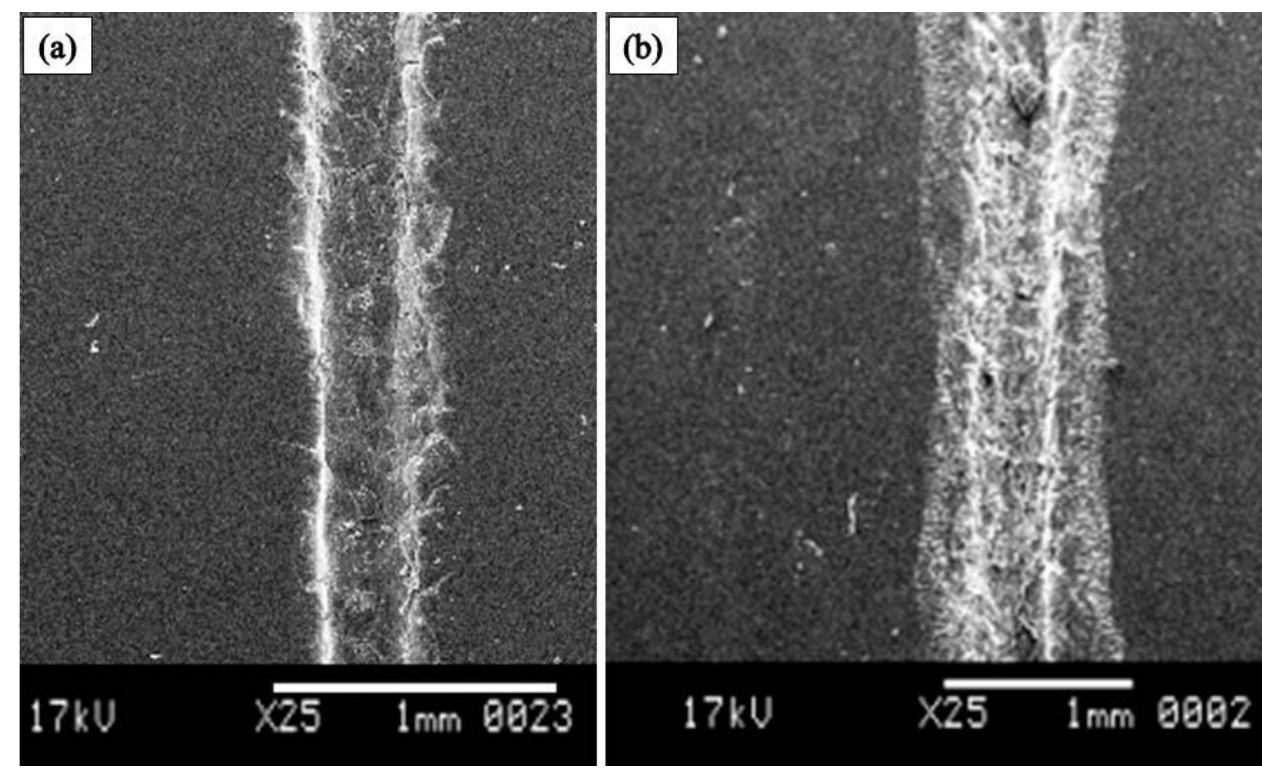

Fig. 4 Typical SEM micrographs of microchannel showing effect of process parameters on overcut (a) minimum overcut (b) maximum overcut

\subsubsection{Effect of control factors on TWR}

It was observed that the influence of control factors on TWR followed the trend which was similar to as that observed in case of MRR and OC. The TWR increased with respect to increase in applied voltage, electrolyte concentration and $\mathrm{T}_{\mathrm{ON}}$. However, TWR decreased 
with higher values of SOD and pulse frequency. As the voltage and concentration increase, heat generation in the machining zone is escalated which leads to higher MRR as well as TWR. Jui et al.[30] reported that TWR reduced with the dropping of the electrolyte concentration of electrolyte. The heat transmitted to the workpiece increases with the electrolyte concentration which (heat transmitted) further is also accountable for the loss of tool material. The decrease in TWR with respect to increase in SOD is due to the fact that each spark occurred between the neighboring point of the cathode tool and work sample and each sparks melts a smaller quantity of material from both [29]. Table 4 shows that factor applied voltage $(70.44 \%)$ is the most influential factor followed by stand-off-distance $(5.44 \%)$ and electrolyte concentration $(5.10 \%)$ on overcut based on ANOVA by considering 95\% confidence level. Figure 5 shows the SEM (Make: Zeiss) micrograph of ruptured WC tool tip. From the Figure, it was observed that micro size of tool material worn out due to increase in voltage and concentration. A part of discharge energy is transferred to the cathode surface which fuses and evaporates a small portion of the cathode material. Since, the tool tip is the sharpest edge, it receives large amount of thermal energy and therefore, subjected to higher wear compared to the stem portion of the tool [24].

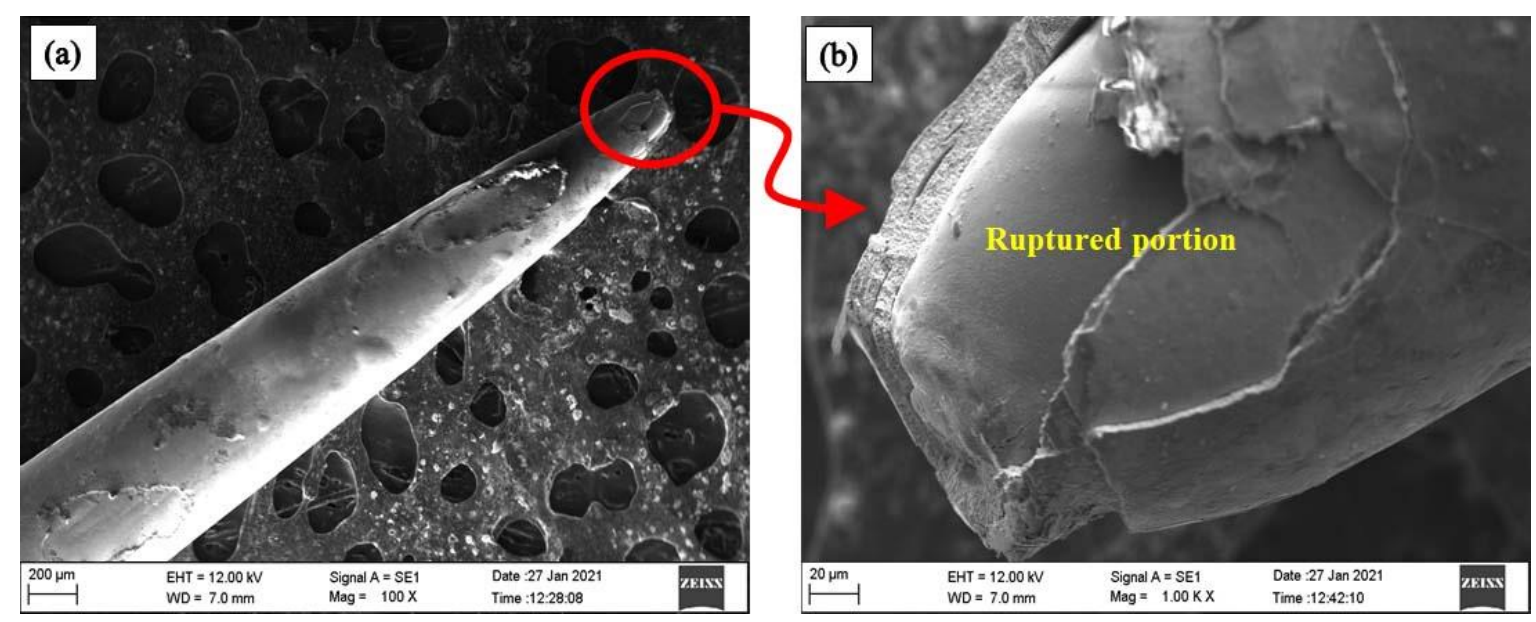

Fig. 5 Typical SEM micrograph showing tool wear (a) tool tip (b) magnified view

\subsection{Multi response optimization through Taguchi-GRA}

The assessment of optimal process factors for a precise machining practice is an important assignment for researchers [12]. Further, GRA was implemented to resolve the problem of multiple quality characteristics[31] since MRR, OC and TWR were not interconnected mutually and independent with process parameters. Consequently, optimization method was stretched for the complete estimation of multiple quality characteristics by producing microchannel in silica glass using ECDM process through GRA. The performance of ECDM 
process was enhanced by defining the objective as to maximize the MRR and minimize the overcut and TWR of machined section. This method determined that experimental trial with highest GRG is closest to optimum solution. The various steps followed in this method as discussed in following sections.

\subsubsection{Normalizing the data}

For normalization of data for the MRR, the larger-the-better performance characteristic was considered and is expressed in Eq. 1. On the other hand for OC and TWR, the smaller-thebetter performance characteristic was considered, and the same has been expressed in Eq. 2 [32].

$$
\begin{aligned}
& \mathrm{X}_{\mathrm{i}}=\frac{Y_{i}-Y_{\min }}{Y_{\text {max }}-Y_{\min }} \\
& \mathrm{X}_{\mathrm{i}}=\frac{Y_{\text {max }}-Y_{i}}{Y_{\text {max }}-Y_{\min }}
\end{aligned}
$$

where $X_{i}$ is the normalized value, $Y_{i}$ is the measured response value (i=1,2, 3... 27 trials), $\mathrm{Y}_{\min }$ and $\mathrm{Y}_{\max }$ are minimum and maximum values of respective responses.

\subsubsection{Calculation of deviation sequence}

Deviation sequence is the difference between the reference value and normalized value obtained in the section 3.2.1, obtained value lies between 0 to 1 . Deviation sequence was calculated using Eq. 3.

$$
\Delta_{i}=X_{r}-X_{i}
$$

where, $\Delta_{i}$ is the deviation sequence, $X_{r}$ is the reference value considered as one [14] and $X_{i}$ is the normalized value obtained.

\subsubsection{Computation of grey relational co-efficient (GRC)}

The GRCs of MRR, OC and TWR were computed by using the Eq. 4. $\zeta$ is distinguishing coefficient. Lesser the value of $\zeta$, greater is the distinguishing capacity. In this study, value of $\zeta$ assumed in the range of $0<\zeta<1$ i.e. $\zeta=0.5$.

$$
G R C=\xi_{i}=\frac{\Delta_{\min }-\zeta \Delta_{\max }}{\Delta_{i}-\zeta \Delta_{\max }}
$$


where $\xi_{i}$ is the GRC, $\Delta_{i}$ is the deviation sequence of $i^{\text {th }}$ trial, $\Delta_{\min }$ and $\Delta_{\max }$ are smallest and largest values of $\Delta_{i}$ for respective responses.

\subsubsection{Computation of grey relational grade (GRG)}

GRG was computed by averaging the GRC values related to each performance characteristic. GRG values were computed using Eq. 5 [13].

$$
G R G=\gamma_{i}=\frac{1}{n} \sum_{1}^{n} \xi_{i}
$$

Where $\xi_{i}$ is the GRC, $\mathrm{n}$ is number of response variables i.e. 3 (MRR, OC and TWR). The larger GRG provides better performance characteristics[12], which provides optimum MRR, OC and TWR. Further, GRG values are ranked from higher to lower. The results obtained from various steps of Taguchi-GRA are tabulated in Table 5.

Table 5 Computing GRCs, GRGs and ranking

\begin{tabular}{|c|c|c|c|c|c|c|c|c|c|c|c|c|c|c|}
\hline \multirow{2}{*}{$\begin{array}{l}\text { Run } \\
\text { No. }\end{array}$} & \multicolumn{3}{|c|}{ Output responses } & \multicolumn{3}{|c|}{ Normalized } & \multicolumn{3}{|c|}{ Deviation sequence } & \multicolumn{3}{|c|}{$\begin{array}{c}\text { Grey Relation } \\
\text { Co-efficient }\end{array}$} & \multirow{2}{*}{ GRG } & \multirow{2}{*}{$\begin{array}{l}\text { GRA } \\
\text { Rank }\end{array}$} \\
\hline & $\begin{array}{c}\text { MRR } \\
(\mathrm{mg} / \mathrm{hr})\end{array}$ & $\begin{array}{c}\mathrm{OC} \\
(\mu \mathrm{m})\end{array}$ & $\begin{array}{c}\text { TWR } \\
(\mathrm{mg} / \mathrm{hr})\end{array}$ & MRR & $\mathrm{OC}$ & TWR & MRR & $\mathrm{OC}$ & TWR & MRR & $\mathrm{OC}$ & TWR & & \\
\hline 1 & 56.325 & 124.717 & 0.112 & 0.136 & 0.871 & 0.872 & 0.864 & 0.129 & 0.128 & 0.367 & 0.795 & 0.796 & 0.653 & 4 \\
\hline 2 & 57.305 & 128.644 & 0.116 & 0.155 & 0.839 & 0.839 & 0.845 & 0.161 & 0.161 & 0.372 & 0.757 & 0.757 & 0.628 & 5 \\
\hline 3 & 58.970 & 131.587 & 0.119 & 0.186 & 0.815 & 0.810 & 0.814 & 0.185 & 0.190 & 0.380 & 0.730 & 0.724 & 0.612 & 8 \\
\hline 4 & 58.420 & 130.119 & 0.117 & 0.176 & 0.827 & 0.825 & 0.824 & 0.173 & 0.175 & 0.378 & 0.743 & 0.740 & 0.620 & 6 \\
\hline 5 & 59.010 & 131.060 & 0.118 & 0.187 & 0.819 & 0.817 & 0.813 & 0.181 & 0.183 & 0.381 & 0.735 & 0.732 & 0.616 & 7 \\
\hline 6 & 62.370 & 139.432 & 0.126 & 0.249 & 0.751 & 0.757 & 0.751 & 0.249 & 0.243 & 0.400 & 0.667 & 0.673 & 0.580 & 9 \\
\hline 7 & 49.040 & 108.951 & 0.096 & 0.000 & 1.000 & 1.000 & 1.000 & 0.000 & 0.000 & 0.333 & 1.000 & 1.000 & 0.778 & 1 \\
\hline 8 & 51.820 & 114.960 & 0.102 & 0.052 & 0.951 & 0.948 & 0.948 & 0.049 & 0.052 & 0.345 & 0.911 & 0.905 & 0.720 & 2 \\
\hline 9 & 53.050 & 117.488 & 0.105 & 0.075 & 0.930 & 0.927 & 0.925 & 0.070 & 0.073 & 0.351 & 0.878 & 0.873 & 0.700 & 3 \\
\hline 10 & 69.860 & 155.694 & 0.142 & 0.390 & 0.618 & 0.620 & 0.610 & 0.382 & 0.380 & 0.450 & 0.567 & 0.568 & 0.529 & 13 \\
\hline 11 & 71.950 & 160.523 & 0.147 & 0.429 & 0.579 & 0.582 & 0.571 & 0.421 & 0.418 & 0.467 & 0.543 & 0.545 & 0.518 & 14 \\
\hline 12 & 74.010 & 165.235 & 0.152 & 0.467 & 0.540 & 0.543 & 0.533 & 0.460 & 0.457 & 0.484 & 0.521 & 0.523 & 0.509 & 16 \\
\hline 13 & 75.870 & 168.723 & 0.156 & 0.502 & 0.512 & 0.511 & 0.498 & 0.488 & 0.489 & 0.501 & 0.506 & 0.505 & 0.504 & 18 \\
\hline 14 & 76.765 & 170.835 & 0.158 & 0.519 & 0.494 & 0.493 & 0.481 & 0.506 & 0.507 & 0.510 & 0.497 & 0.497 & 0.501 & 20 \\
\hline 15 & 83.900 & 186.855 & 0.174 & 0.652 & 0.363 & 0.364 & 0.348 & 0.637 & 0.636 & 0.590 & 0.440 & 0.440 & 0.490 & 24 \\
\hline 16 & 100.19 & 220.300 & 0.207 & 0.957 & 0.090 & 0.093 & 0.043 & 0.910 & 0.907 & 0.921 & 0.355 & 0.355 & 0.544 & 11 \\
\hline 17 & 77.560 & 165.512 & 0.158 & 0.534 & 0.538 & 0.489 & 0.466 & 0.462 & 0.511 & 0.517 & 0.520 & 0.494 & 0.510 & 15 \\
\hline 18 & 84.940 & 189.467 & 0.176 & 0.672 & 0.342 & 0.343 & 0.328 & 0.658 & 0.657 & 0.604 & 0.432 & 0.432 & 0.489 & 26 \\
\hline 19 & 69.275 & 154.505 & 0.141 & 0.379 & 0.628 & 0.630 & 0.621 & 0.372 & 0.370 & 0.446 & 0.573 & 0.575 & 0.531 & 12 \\
\hline 20 & 75.910 & 168.810 & 0.156 & 0.503 & 0.511 & 0.511 & 0.497 & 0.489 & 0.489 & 0.501 & 0.505 & 0.505 & 0.504 & 17 \\
\hline 21 & 76.640 & 178.041 & 0.165 & 0.517 & 0.435 & 0.431 & 0.483 & 0.565 & 0.569 & 0.508 & 0.470 & 0.468 & 0.482 & 27 \\
\hline
\end{tabular}




\begin{tabular}{llllllllllllllll}
22 & 81.250 & 181.024 & 0.168 & 0.603 & 0.411 & 0.411 & 0.397 & 0.589 & 0.589 & 0.557 & 0.459 & 0.459 & 0.492 & 21 \\
23 & 83.820 & 186.733 & 0.173 & 0.651 & 0.364 & 0.365 & 0.349 & 0.636 & 0.635 & 0.589 & 0.440 & 0.440 & 0.490 & 25 \\
24 & 86.715 & 193.222 & 0.180 & 0.705 & 0.311 & 0.312 & 0.295 & 0.689 & 0.688 & 0.629 & 0.421 & 0.421 & 0.490 & 23 \\
25 & 76.680 & 170.658 & 0.158 & 0.517 & 0.496 & 0.495 & 0.483 & 0.504 & 0.505 & 0.509 & 0.498 & 0.498 & 0.501 & 19 \\
26 & 82.765 & 184.313 & 0.171 & 0.631 & 0.384 & 0.384 & 0.369 & 0.616 & 0.616 & 0.576 & 0.448 & 0.448 & 0.491 & 22 \\
27 & 102.47 & 231.325 & 0.218 & 1.000 & 0.000 & 0.000 & 0.000 & 1.000 & 1.000 & 1.000 & 0.333 & 0.333 & 0.556 & 10 \\
\hline
\end{tabular}

From the grey analysis, it has been observed that seventh trial has maximum value of GRG, hence the experimental trial 7 was ranked as first. Therefore, in this work, out of 27 experiments trial 7 was considered as the best run. The process parameters of best run were applied voltage $45 \mathrm{~V}$, electrolyte concentration $25 \mathrm{wt} . \%$, stand-off-distance $1.5 \mathrm{~mm}$, pulse frequency $400 \mathrm{~Hz}$ and pulse-on-time $45 \mu \mathrm{s}\left(\mathrm{A}_{1}-\mathrm{B}_{3}-\mathrm{C}_{3}-\mathrm{D}_{3}-\mathrm{E}_{1}\right)$. Therefore, the outcome of MRR, OC and TWR were $49.040 \mathrm{mg} / \mathrm{hr}, 108.951 \mu \mathrm{m}$ and $0.096 \mathrm{mg} / \mathrm{hr}$ respectively.

However, in order to ensure the result obtained from Table 5, further evaluation of the multiresponse characteristics for the optimal combination of the control factors and their levels was determined by averaging the GRGs. Table 6 presents the optimum process parameters for getting good MRR, OC and TWR, hence the optimal combination from GRG is $\mathrm{A}_{1}-\mathrm{B}_{3}-\mathrm{C}_{3}-$ $\mathrm{D}_{3}-\mathrm{E}_{1}$. Thus a combination of $45 \mathrm{~V}$ applied voltage, $25 \mathrm{wt}$.\% electrolyte concentration, $1.5 \mathrm{~mm}$ stand-off-distance, $400 \mathrm{~Hz}$ pulse frequency and $45 \mu \mathrm{s} \mathrm{T}_{\mathrm{ON}}$ which is same as that observed from Table 5 was achieved.

Table 6 Response table for the GRG

\begin{tabular}{clccccc}
\hline Factor Process parameter & Level 1 & Level 2 & Level 3 & $\begin{array}{c}\text { Total mean } \\
\text { of GRG }\end{array}$ & $\begin{array}{c}\text { Optimum } \\
\text { level }\end{array}$ \\
\hline A & Applied Voltage (V) & $\mathbf{0 . 6 5 6}$ & 0.511 & 0.504 & & $\mathrm{~A}_{1}$ \\
B & Electrolyte Conc. (wt.\%) & 0.552 & 0.531 & $\mathbf{0 . 5 8 8}$ & & $\mathrm{B}_{3}$ \\
C & Stand-off-distance (mm) & 0.545 & 0.547 & $\mathbf{0 . 5 7 9}$ & 0.557 & $\mathrm{C}_{3}$ \\
D & Pulse frequency (Hz) & 0.548 & 0.542 & $\mathbf{0 . 5 8 1}$ & & $\mathrm{D}_{3}$ \\
E & Pulse on time $(\mu \mathrm{s})$ & $\mathbf{0 . 5 7 2}$ & 0.553 & 0.545 & & $\mathrm{E}_{1}$ \\
\hline
\end{tabular}

The graphical representation of the same is depicted through the main effects plot for GRG as shown in Fig. 6. It was noticed that lower applied voltage, higher electrolyte concentration and higher pulse frequency contribute in increasing the GRG. 

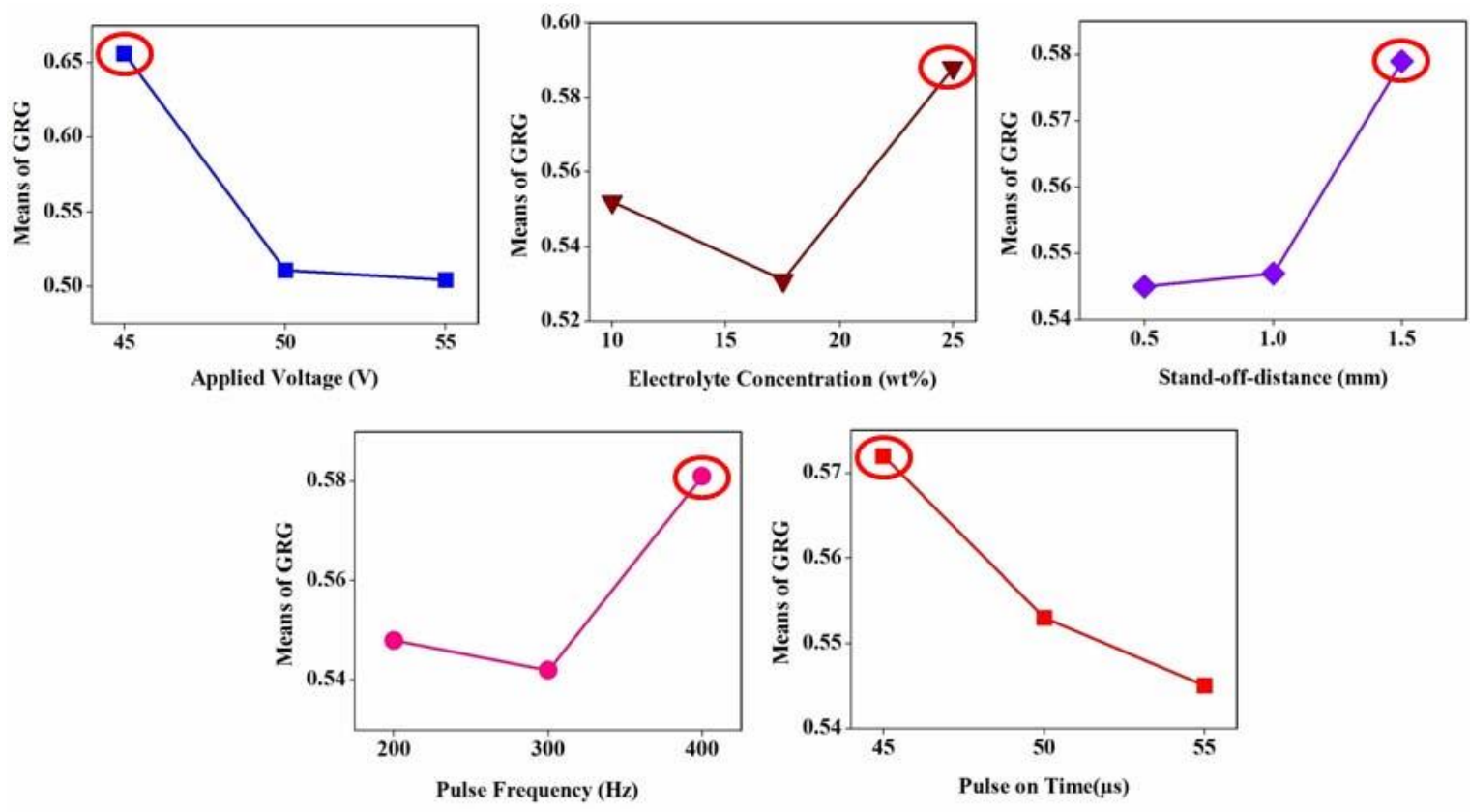

Fig. 6 Main effect plots for GRG (optimum level $\left.A_{1}-B_{3}-C_{3}-D_{3}-E_{1}\right)$

Table 7 ANOVA for GRG values

\begin{tabular}{lccccc}
\hline \multicolumn{1}{c}{ Source } & DOF & Seq SS & Adj MS & \% contribution & Remarks \\
\hline Applied Voltage $(\mathrm{V})$ & 2 & 0.1738 & 0.0869 & 70.33 & Significant \\
Electrolyte Concentration (wt\%) & 2 & 0.0289 & 0.0145 & 11.69 & Significant \\
Stand-off Distance $(\mathrm{mm})$ & 2 & 0.0102 & 0.0051 & 4.13 & Significant \\
Pulse frequency $(\mathrm{Hz})$ & 2 & 0.0123 & 0.0061 & 4.98 & Significant \\
Pulse on time $(\mu \mathrm{s})$ & 2 & 0.0049 & 0.0024 & 1.98 & Insignificant \\
Residual error & 16 & 0.0170 & 0.00106 & 6.89 & \\
Total & 26 & 0.2471 & & & \\
\hline
\end{tabular}

Table 7 represents the ANOVA for MRR, OC and TWR which gives the effective level of selected factors on the desired responses. It was observed that applied voltage is the mostly influencing factor affecting response variables. The electrolyte concentration also marginally influences the MRR, OC and TWR. Furthermore, SOD and pulse frequency have slight effects on the output characteristics. This influence is identified from the percentage contribution calculated at $95 \%$ confidence. The interaction effect of all the parameters does not have major effect on the response variables; hence, it is pooled to error. 


\subsection{Confirmation test}

The confirmation test for the achieved optimum combination was conducted once again to confirm the quality features of producing microchannel in silica glass using ECDM process. Table 5 presents the highest GRG highlighting the combination of control factors as $\mathrm{A}_{1}-\mathrm{B}_{3}$ $\mathrm{C}_{3}-\mathrm{D}_{3}-\mathrm{E}_{1}$. Regression equations were formulated as in Eq. 6-8 using MINITAB software to associate the interaction and higher-order effects of the previously mentioned factors, employing the related experimental data as noticed during the course of micro-machining.

$$
\begin{aligned}
& \text { MRR }=-72.8+2.547 \times \mathrm{A}_{1}+0.506 \times \mathrm{B}_{3}-8.31 \times \mathrm{C}_{3}-0.0275 \times \mathrm{D}_{3}+0.513 \times \mathrm{E}_{1} \\
& \text { Overcut }=-175.6+5.796 \times \mathrm{A}_{1}+1.002 \times \mathrm{B}_{3}-16.89 \times \mathrm{C}_{3}-0.0632 \times \mathrm{D}_{3}+1.311 \times \mathrm{E}_{1} \\
& \text { TWR }=-0.1876+0.005767 \times \mathrm{A}_{1}+0.001050 \times \mathrm{B}_{3}-0.01737 \times \mathrm{C}_{3}-0.000064 \times \mathrm{D}_{3}+0.001316 \times \mathrm{E}_{1}
\end{aligned}
$$

Table 8 Predicted and confirmation test results for optimal combination

\begin{tabular}{lcccc}
\hline Output characteristics & Optimal combination & Predicted & Experimental & Error \% \\
\hline MRR $(\mathrm{mg} / \mathrm{hr})$ & $\mathrm{A}_{1}-\mathrm{B}_{3}-\mathrm{C}_{3}-\mathrm{D}_{3}-\mathrm{E}_{1}$ & 54.085 & 52.109 & 3.65 \\
Overcut $(\mu \mathrm{m})$ & $(45 \mathrm{~V}-25 \mathrm{wt} \%-1.5 \mathrm{~mm}-$ & 118.65 & 112.80 & 4.93 \\
TWR $(\mathrm{mg} / \mathrm{hr})$ & $400 \mathrm{~Hz}-45 \mu \mathrm{s})$ & 0.10573 & 0.0996 & 5.797 \\
\hline
\end{tabular}

Table 8 represents comparison between experimental results and predicted results for optimum combination $\left(\mathrm{A}_{1}-\mathrm{B}_{3}-\mathrm{C}_{3}-\mathrm{D}_{3}-\mathrm{E}_{1}\right)$. Confirmation experimental results designate a good agreement between the experimental results and predicted values.

\subsection{Microstructure study of machined surface}

The microstructure investigation of SEM images was carried out on machined surface for optimum combination $\left(\mathrm{A}_{1}-\mathrm{B}_{3}-\mathrm{C}_{3}-\mathrm{D}_{3}-\mathrm{E}_{1}\right)$ setting. In every discharge, removal of material from the work piece takes place due to a portion of thermal energy generated in electrolyte concentration. Figure 7(a) shows the SEM micrograph of microchannel formed in silica glass with a small amount of overcut. Figure 7(b), depicts the magnified view in which sharp edges and deep grooves confirmed the material removal in large chunks due to the combination of the applied voltage, concentration and pulse frequency [28]. Deep grooves are obtained at several locations due to interlinking of sparks generated during machining. Furthermore, the presence of deeper grooves on the surface due to increase in applied voltage and effect of pulse parameters increases indentation of sparks on machined surface [21].

Further, the machined surface also appears to be irregular which is attributed to the deposition of re-solidified particles on the previously machined surface which leads to the formation of sharp edges. 


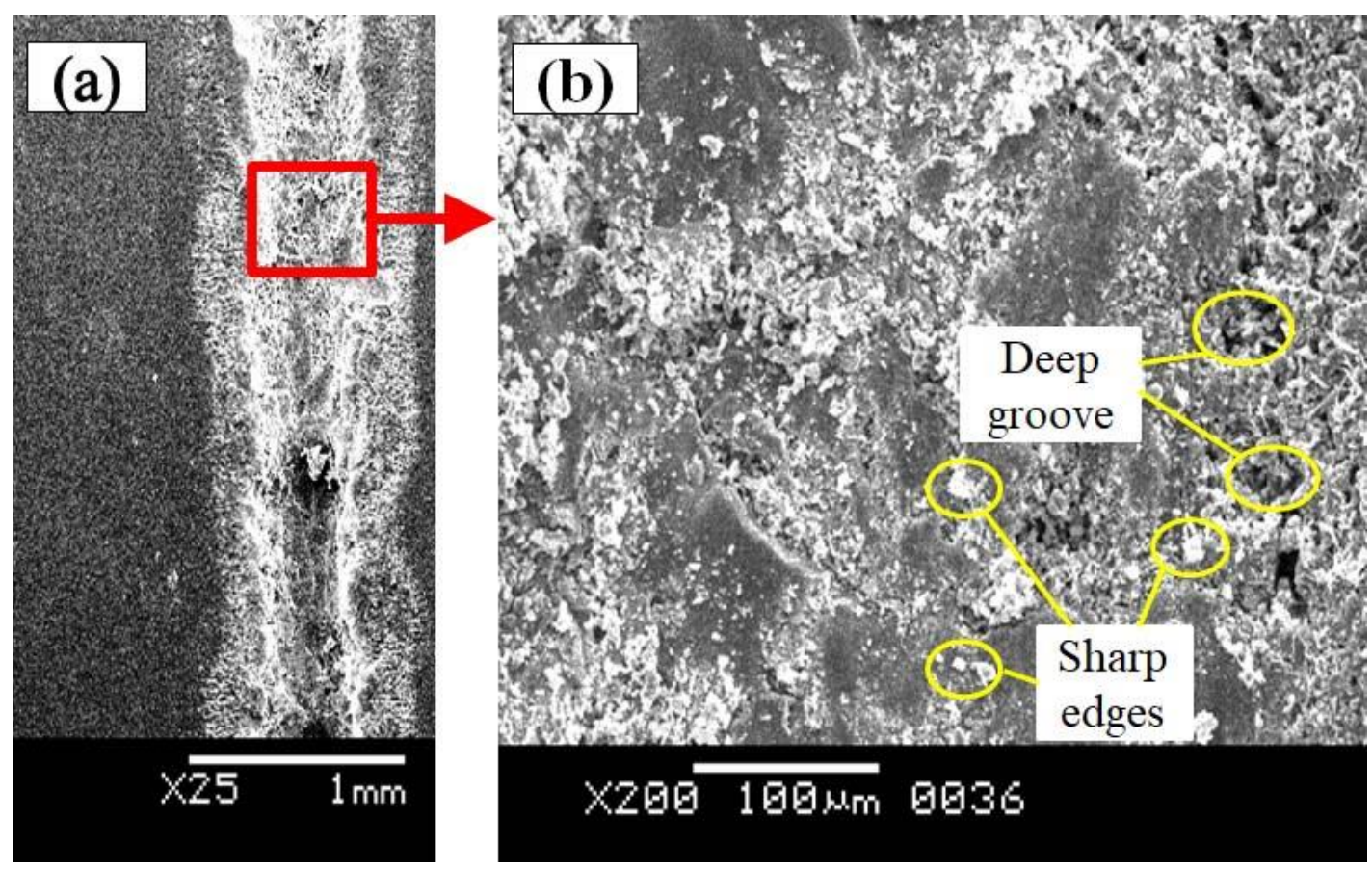

Fig. 7 SEM image of the confirmation test (a) machined groove (b) magnified view

\section{Conclusion}

In the present work ECDM setup has been developed and machining of $250 \mu \mathrm{m}$ microchannel in silica glass was successfully carried out followed by the optimization of process parameters using GRA. Based on the experimentation results, following conclusions have been drawn.

(i) MRR, OC and TWR to a great extent depend on voltage and concentration. As the voltage and concentration increased, MRR, OC and TWR also increased. On the other hand as SOD and pulse frequency increased, MRR, OC and TWR decreased.

(ii) As the SOD increases the kinetics of electrochemical reactions diminishes, resulting in decrease of sparking phenomenon.

(iii) The optimum combination of control factors obtained through GRA was observed to be $\mathrm{A}_{1}-\mathrm{B}_{3}-\mathrm{C}_{3}-\mathrm{D}_{3}-\mathrm{E}_{1}(45 \mathrm{~V}-25 \mathrm{wt} . \%-1.5 \mathrm{~mm}-400 \mathrm{~Hz}-45 \mu \mathrm{s})$.

(iv) Based on ANOVA results of GRG it was noticed that, applied voltage has major influence on MRR, OC and TWR followed by electrolyte concentration, pulse frequency and SOD.

(v) Confirmation experiment results and predicted values were found to be in good agreement with $3.65 \%, 4.93 \%$ and $5.797 \%$ for MRR, OC and TWR respectively.

(vi) The microstructural investigation of the machined surface reveals the formation of deep grooves and sharp edges at several locations. 


\section{Funding statement: (Not applicable)}

This work is self-financed and is not funded by any of the government/private/organizations.

\section{Conflict of interest: (Not applicable)}

The authors do not have any conflicts of interest that may have a direct bearing on the subject matter of the article and it will not reflect any possible bias in either the exposition or the conclusions presented.

\section{Author contribution:}

All the authors have equally contributed in terms of experimentation and writing of manuscript.

\section{Availability of data and material:}

The datasets generated during and/or analyzed during the current study are available with authors and would be provided to the journal if required.

\section{Compliance with ethical standards: (Not applicable)}

This article does not contain any studies with human participants or animals performed by any of the authors.

\section{Consent to participate:}

The authors are free to contact any of the people involved in the research to seek further clarification and information. We understand that under freedom of information legalisation and entitled to access the information provided at any time while it is in storage as specified in the manuscript.

\section{Consent for Publication:}

The authors give their consent for the publication of identifiable details, which can include photograph(s) and/or details within the manuscript to be published in Silicon Journal.

\section{Acknowledgments:}

The authors are thankful to Alva's Institute of Engineering and Technology, Moodabidri, Karnataka, India for permitting to conduct the experimentation work. 


\section{References}

[1] Mallick, B. et al. (2014) 'Multi criteria optimization of electrochemical discharge micro-machining process during micro-channel generation on glass', Applied Mechanics and Materials, 592-594, pp. 525-529. doi: 10.4028/www.scientific.net/AMM.592-594.525.

[2] Wüthrich, R. and Fascio, V. (2005) 'Machining of non-conducting materials using electrochemical discharge phenomenon - An overview', International Journal of Machine Tools and Manufacture, 45(9), pp. 1095-1108. doi: 10.1016/j.ijmachtools.2004.11.011.

[3] Sharma, P. et al. (2020) 'Experimental investigations into alumina ceramic micromachining by Experimental investigations into alumina ceramic process micromachining by electrochemical discharge machining', Procedia Manufacturing, 48(2019), pp. 244-250. doi: 10.1016/j.promfg.2020.05.044.

[4] Bellubbi, S., Naik, R. and Sathisha, N. (2020) 'An experimental study of process parameters on material removal rate in ECDM process', Materials Today: Proceedings. doi: https://doi.org/10.1016/j.matpr.2020.01.510.

[5] Furutani, K. and Maeda, H. (2008) 'Machining a glass rod with a lathe-type electro-chemical discharge machine', Journal of Micromechanics and Microengineering, 18(6). doi: 10.1088/0960-1317/18/6/065006.

[6] Mediliyegedara, T. K. K. R. et al. (2006) 'Designing steps and simulation results of a pulse classification system for the Electro Chemical Discharge Machining (ECDM) process - An artificial neural network approach', Advances in Soft Computing, 34, pp. 343-352. doi: 10.1007/3-540-31662-0_27.

[7] Sathisha N., Hiremath, S. S. and J, S. (2014) 'Prediction of Material Removal Rate using Regression Analysis and Artificial Neural Network of ECDM Process', International Journal of Recent advances in Mechanical Engineering, 3(2), pp. 69-81. doi: 10.14810/ijmech.2014.3207.

[8] Bhattacharyya, B. (2017) 'Analysis on electrochemical discharge machining during micro-channel cutting on glass B . Mallick, B . R . Sarkar*, B . Doloi’, 7(1), pp. 32-50.

[9] Hajian, M., Razfar, M. R. and Movahed, S. (2016) 'An experimental study on the effect of magnetic field orientations and electrolyte concentrations on ECDM milling performance of glass', Precision Engineering, 45, pp. 322-331. doi: https://doi.org/10.1016/j.precisioneng.2016.03.009.

[10] Yang, C.-K. et al. (2010) 'Effect of surface roughness of tool electrode materials in ECDM performance', International Journal of Machine Tools and Manufacture, 50(12), pp. 1088-1096. doi: https://doi.org/10.1016/j.ijmachtools.2010.08.006.

[11] Pawar, P., Ballav, R. and Kumar, A. (2017) 'Review on Material Removal Technology of Soda-Lime Glass Material', Indian Journal of Science and Technology, 10(8), pp. 1-7. doi: 10.17485/ijst/2017/v10i8/102698.

[12] Garg, M. P., Singh, M. and Singh, S. (2019) Micro-machining and Process Optimization of Electrochemical Discharge Machining ( ECDM ) Process by GRA Method. Springer International Publishing. doi: 10.1007/978-3-030-16943-5.

[13] Badiger, R. I., Narendranath, S. and Srinath, M. S. (2019) 'Optimization of Process Parameters by Taguchi Grey Relational Analysis in Joining Inconel-625 Through Microwave Hybrid Heating', Metallography, Microstructure, and Analysis, 8(1), pp. 92-108. doi: 10.1007/s13632-018-0508-4.

[14] Naik, G. and .S, N. (2018) 'OPTIMIZATION OF WIRE-ED TURNING PROCESS PARAMETERS BY TAGUCHI-GREY RELATIONAL ANALYSIS', i-manager's Journal on Mechanical Engineering, 8, p. 1. 
doi: $10.26634 / j m e .8 .2 .14206$.

[15] Sathisha, N., Somashekhar, S. H., Shivakumar, J., \& Badiger, R. I. (2013). Parametric optimization of electro chemical spark machining using taguchi based grey relational analysis. IOSR Journal of Mechanical and Civil Engineering (IOSR-JMCE), 46-52.

[16] Madhavi, J. B. and Hiremath, S. S. (2019) 'Machining and Characterization of Channels and Textures on Quartz Glass Using $\mu$-ECDM Process'.

[17] Dhanvijay, M. R., Kulkarni, V. A. and Doke, A. (2019) 'Experimental Investigation and Analysis of Electrochemical Discharge Machining ( ECDM ) On Fiberglass Reinforced Plastic ( FRP )', Journal of The Institution of Engineers (India): Series C. doi: 10.1007/s40032-019-00524-y.

[18] Paul, L. and Kumar, A. B. (2018) 'IMPROVEMENT IN MICRO FEATURE GENERATION IN ECDM PROCESS WITH', pp. 1-6.

[19] Paul, L., \& Antony, D. (2018, August). Effect of tool diameter in ECDM process with powder mixed electrolyte. In IOP Conference Series: Materials Science and Engineering (Vol. 396, No. 1, p. 012070). IOP Publishing.

[20] Rajput, V. (2020) 'Multi-Response Optimization of ECDM Parameters for Silica ( Quartz ) Using Grey Relational Analysis'.

[21] Paul, L., \& Hiremath, S. S. (2014). Evaluation of process parameters of ECDM using grey relational analysis. Procedia Materials Science, 5, 2273-2282.

[22] Nagaraj, Y. (2020) 'Prediction of Material Removal Rate and Surface Roughness in Hot Air Assisted Hybrid Machining on Soda-Lime-Silica Glass using Regression Analysis and Artificial Neural Network'.

[23] Singh, B. and Vaishya, R. O. (2017) 'Analyses of Output Parameters of ECDM Using Different Abrasives-A Review', International Journal of Materials Science, 12(2), pp. 307-314. Available at: http://www.ripublication.com.

[24] Elhami, S. and Razfar, M. R. (2018) 'Effect of ultrasonic vibration on the single discharge of electrochemical discharge machining', Materials and Manufacturing Processes, 33(4), pp. 444-451. doi: 10.1080/10426914.2017.1328113.

[25] Naik, G. M. et al. (2020) 'An investigation on effects ofwire-EDTmachining parameters onsurfaceroughnessof INCONEL 718', Materials Today: Proceedings. doi: https://doi.org/10.1016/j.matpr.2020.03.031.

[26] Sreenivasulu, R. and Rao, C. S. (2013) 'Design of Experiments based Grey Relational Analysis in Various Machining Processes - A Review', Research Journal of Engineering Sciences, 2(1), pp. 21-26.

[27] Sachin, B., S. Narendranath, and D. Chakradhar. "Experimental evaluation of diamond burnishing for sustainable manufacturing." Materials Research Express 5, no. 10 (2018): 106514.

[28] Sindhu, D., Thakur, L. and Chandna, P. (2019) 'Multi-objective Optimization of Rotary Ultrasonic Machining Parameters for Quartz Glass Using Taguchi-Grey Relational Analysis (GRA)', Silicon, 11(4), pp. 2033-2044. doi: 10.1007/s12633-018-0019-6.

[29] Jahan, M. P., Rahman, M. and Wong, Y. S. (2014) Micro-Electrical Discharge Machining (MicroEDM): Processes, Varieties, and Applications, Comprehensive Materials Processing. Elsevier. doi: 10.1016/B978-0-08-096532-1.01107-9.

[30] Jui, S. K., Kamaraj, A. B. and Sundaram, M. M. (2013) 'High aspect ratio micromachining of glass by 
electrochemical discharge machining ( ECDM )', Journal of Manufacturing Processes, 15(4), pp. 460-466. doi: 10.1016/j.jmapro.2013.05.006.

[31] Nagaraj, Y. et al. (2021) 'Parametric optimization on hot air assisted hybrid machining of soda-lime glass using Taguchi based grey relational analysis', Multiscale and Multidisciplinary Modeling, Experiments and Design. doi: 10.1007/s41939-020-00085-z.

[32] Stalin, B. et al. (2019) 'Optimization of wear parameters using Taguchi grey relational analysis and ANN-TLBO algorithm for silicon nitride filled AA6063 matrix composites', Materials Research Express, 6(10), p. 106590. doi: 10.1088/2053-1591/ab3d90. 
Figures

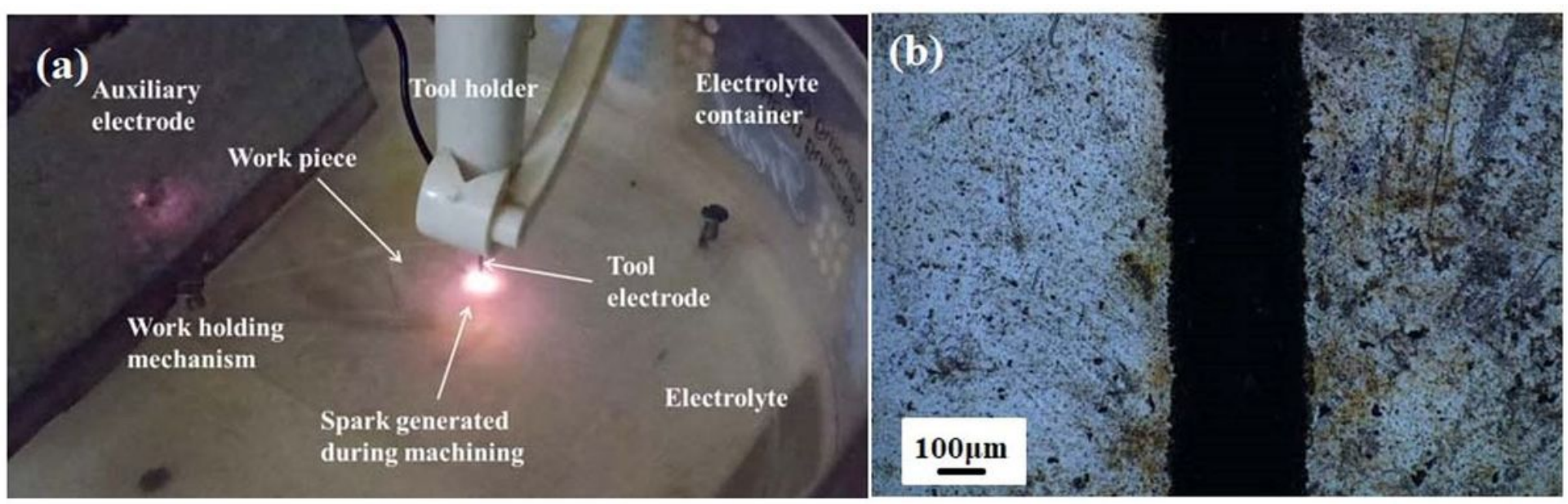

Figure 1

Images of (a) ECDM (b) Optical image of Silica glass with micro-channel

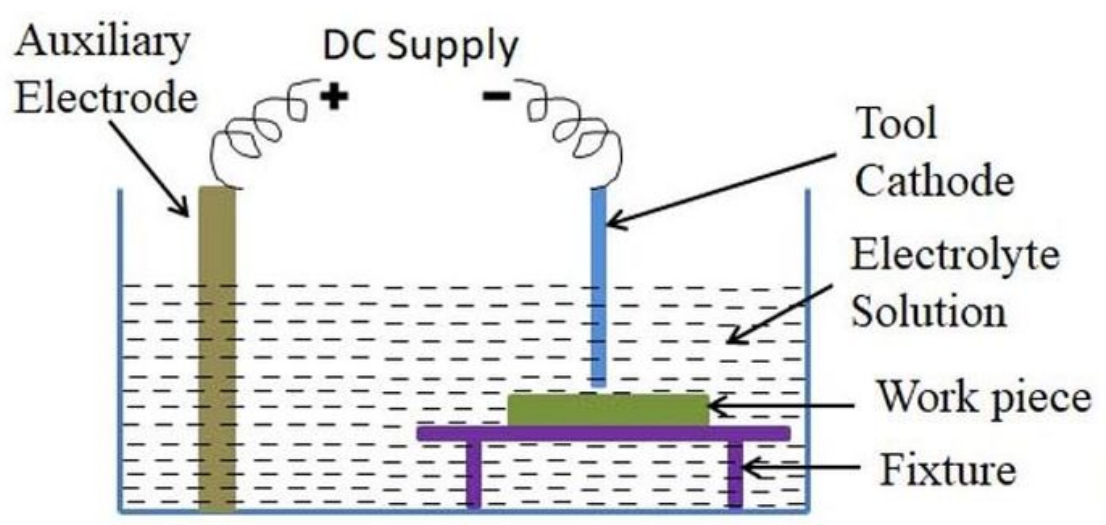

(a)

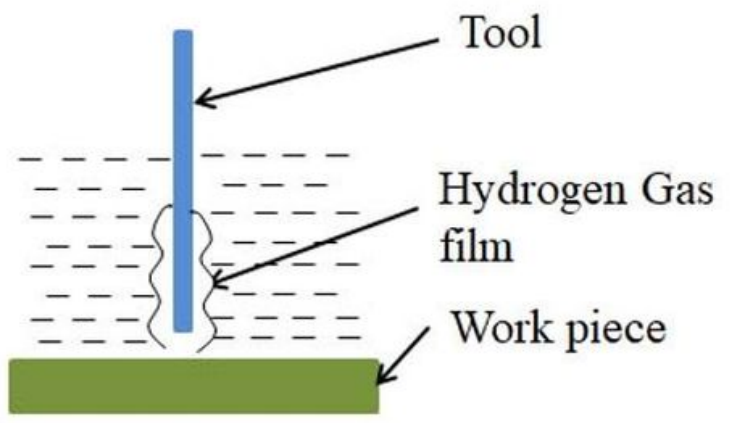

(c)

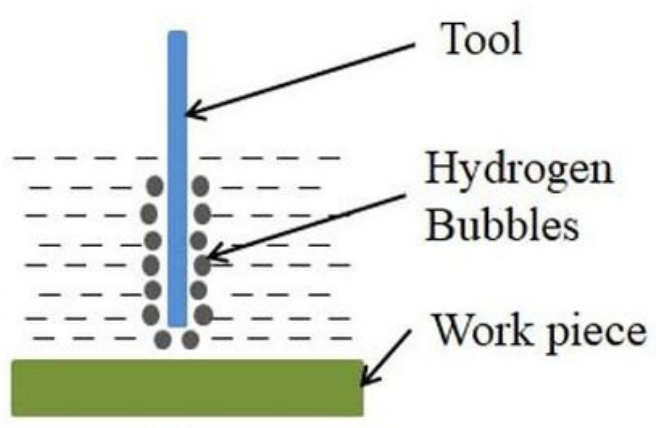

(b)

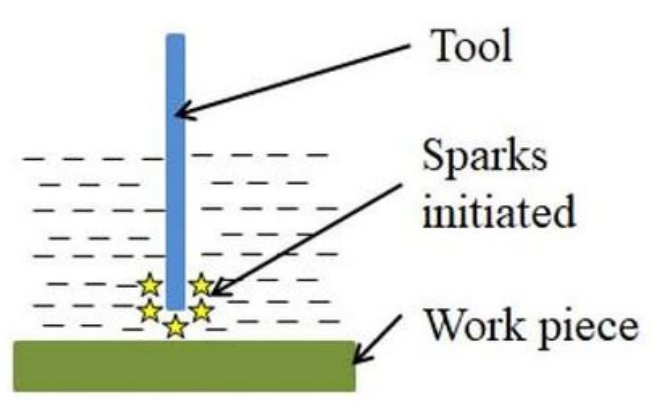

(d)

\section{Figure 2}

(a) Schematic view of ECDM setup (b) Hydrogen bubbles formation (c) Hydrogen gas film formation (d) Spark initiation 


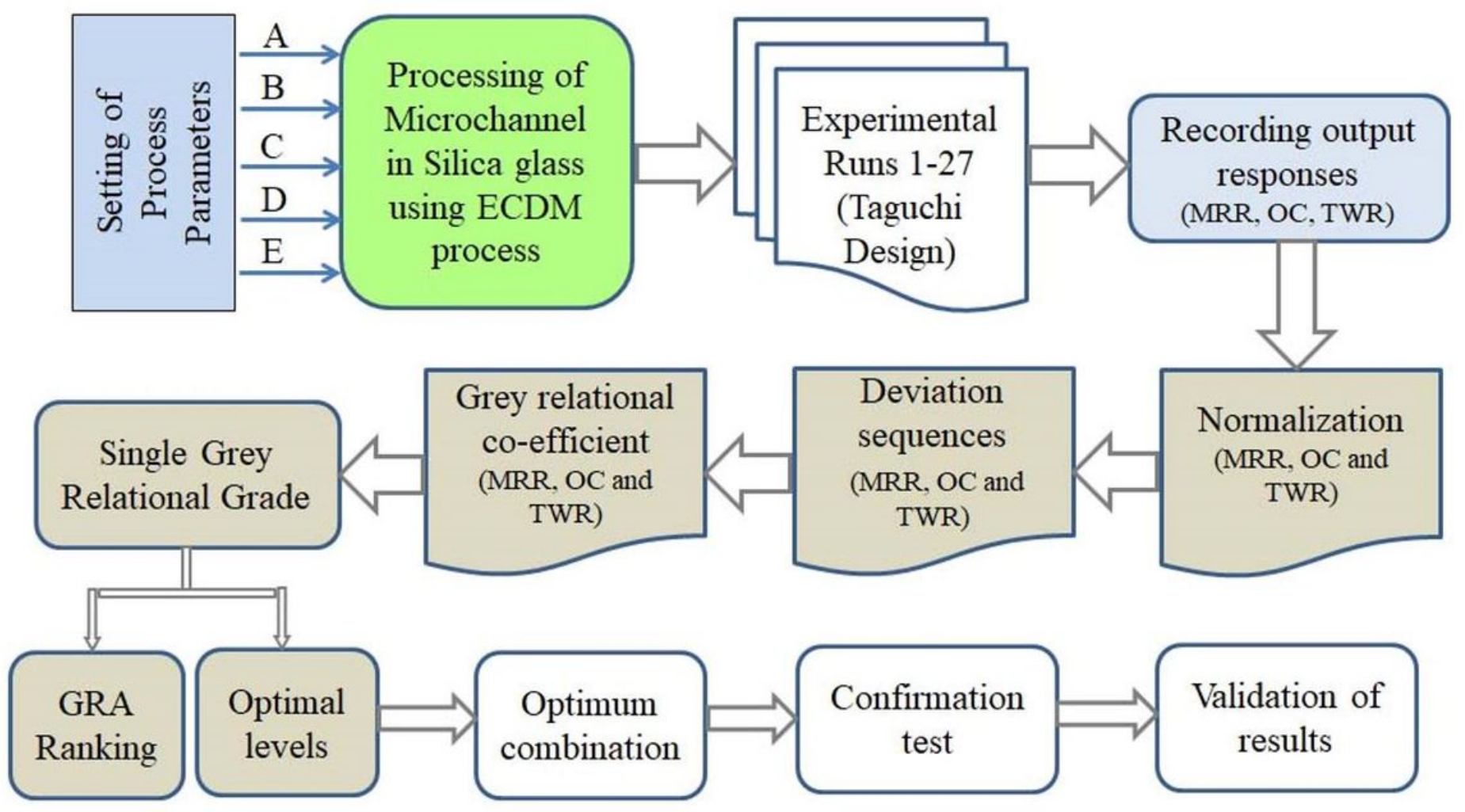

Figure 3

Steps involved in GRA method
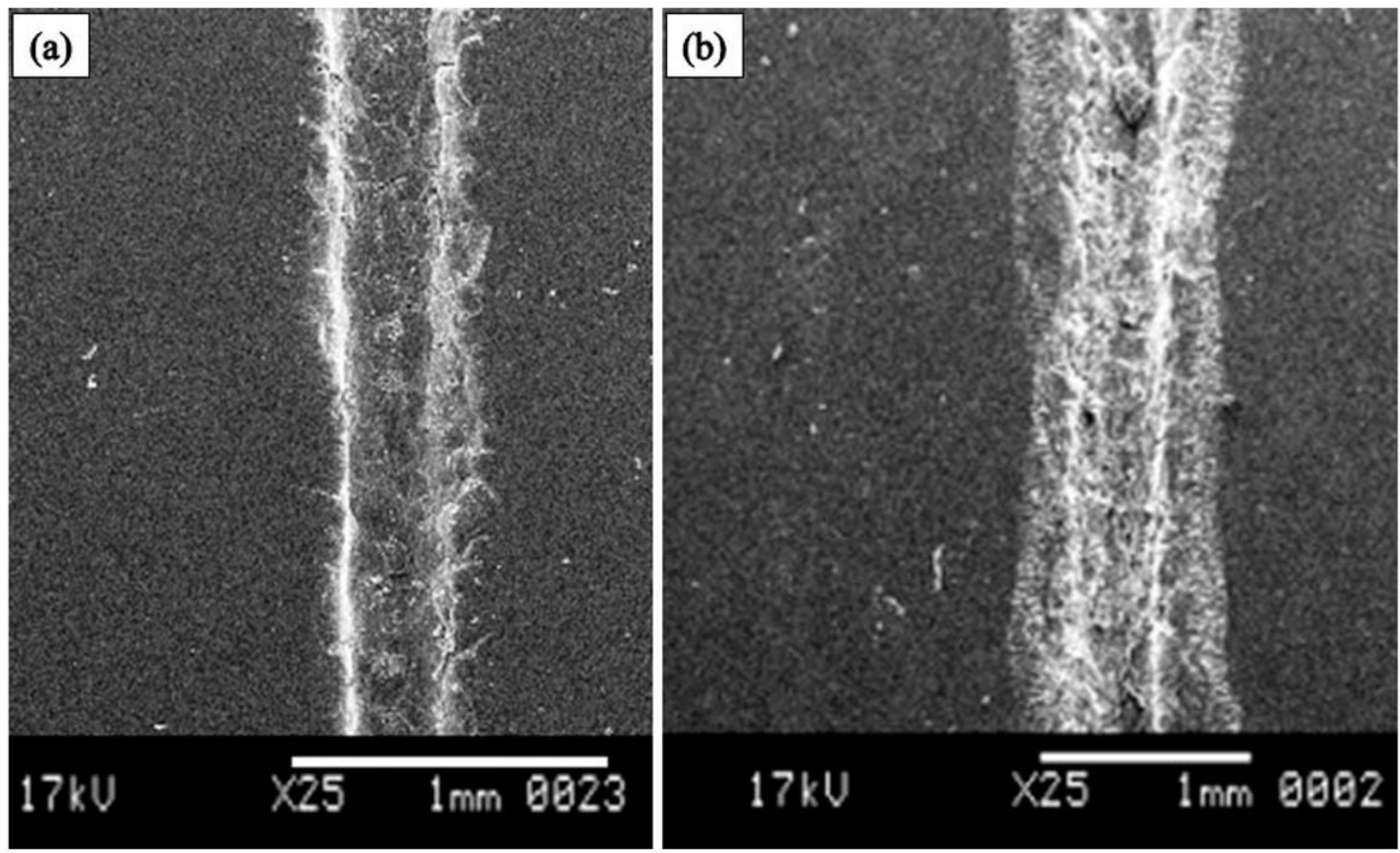
Figure 4

Typical SEM micrographs of microchannel showing effect of process parameters on overcut (a) minimum overcut (b) maximum overcut

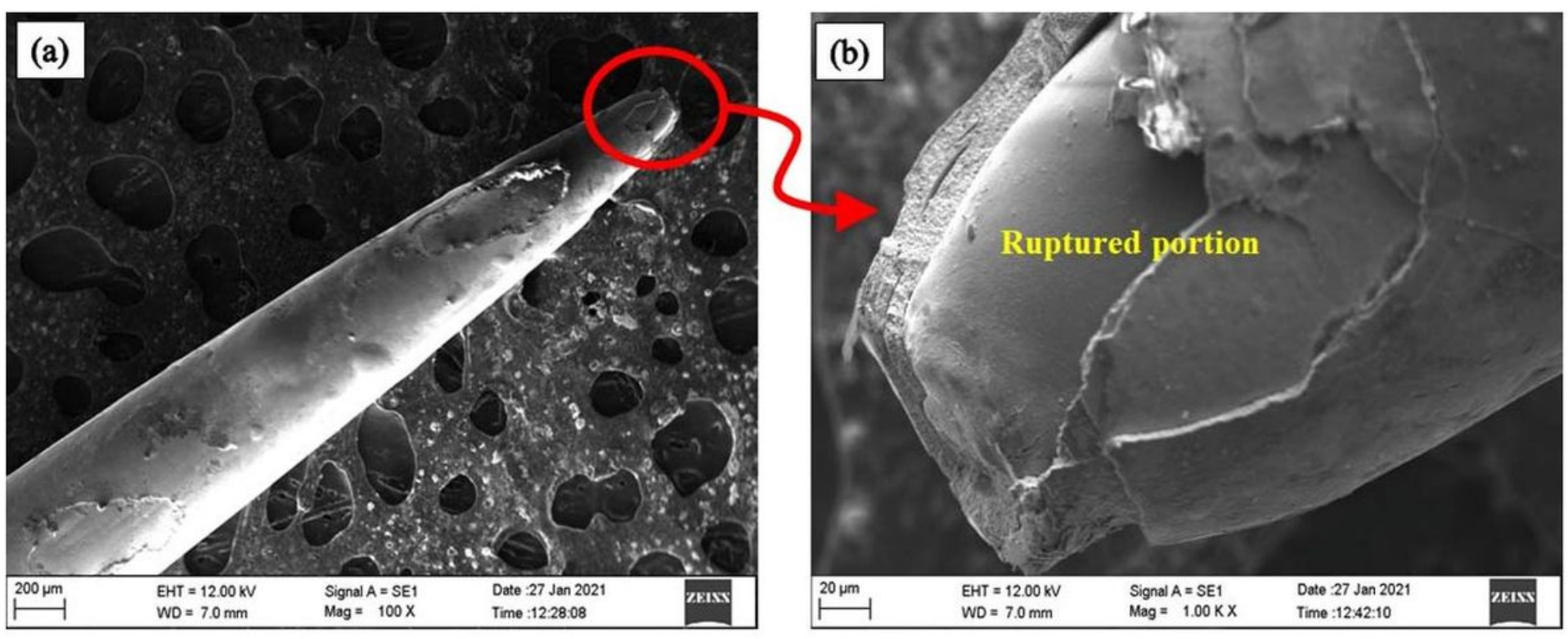

Figure 5

Typical SEM micrograph showing tool wear (a) tool tip (b) magnified view
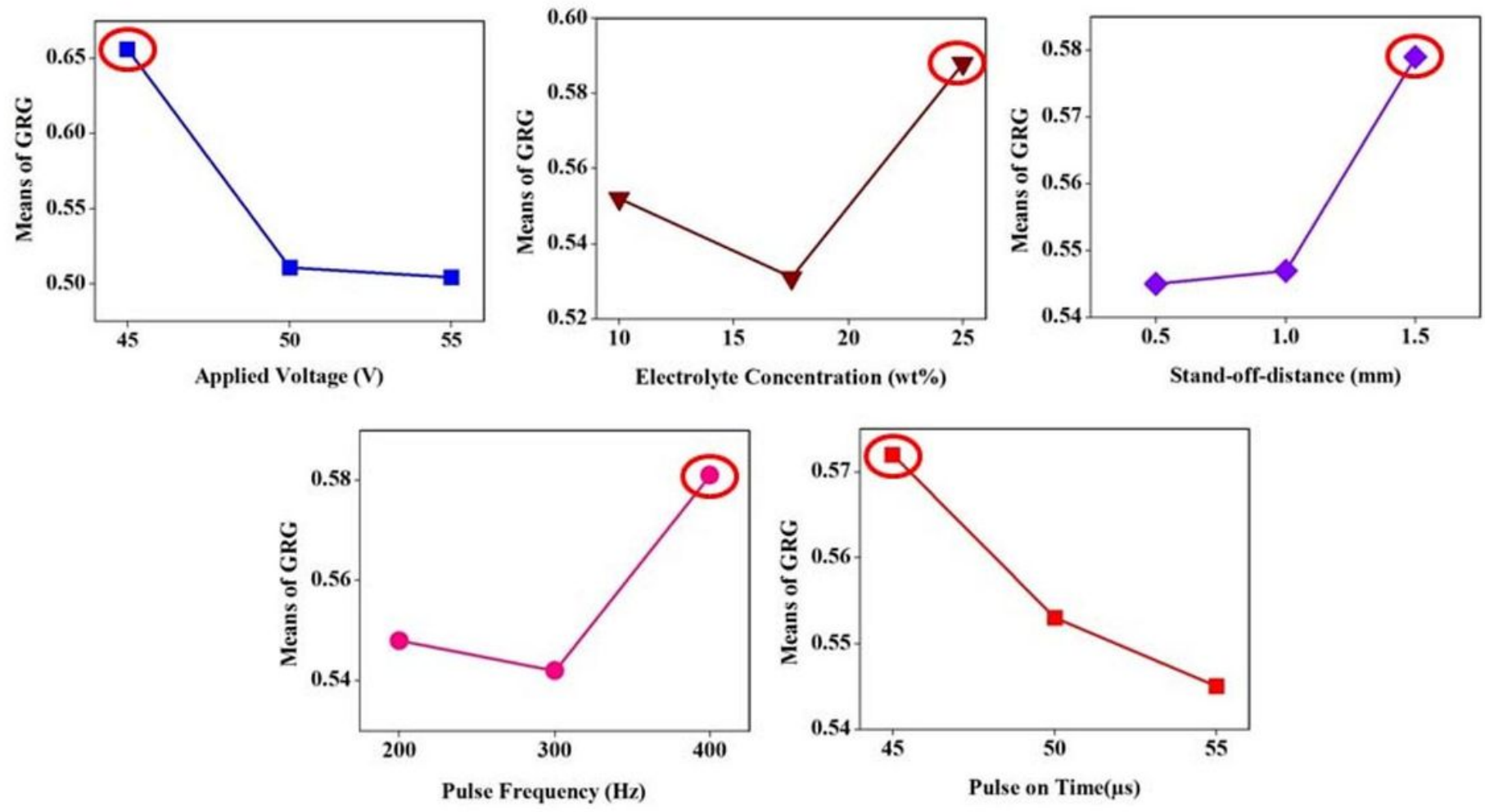

Figure 6 
Main effect plots for GRG (optimum level A1-B3-C3-D3-E1)

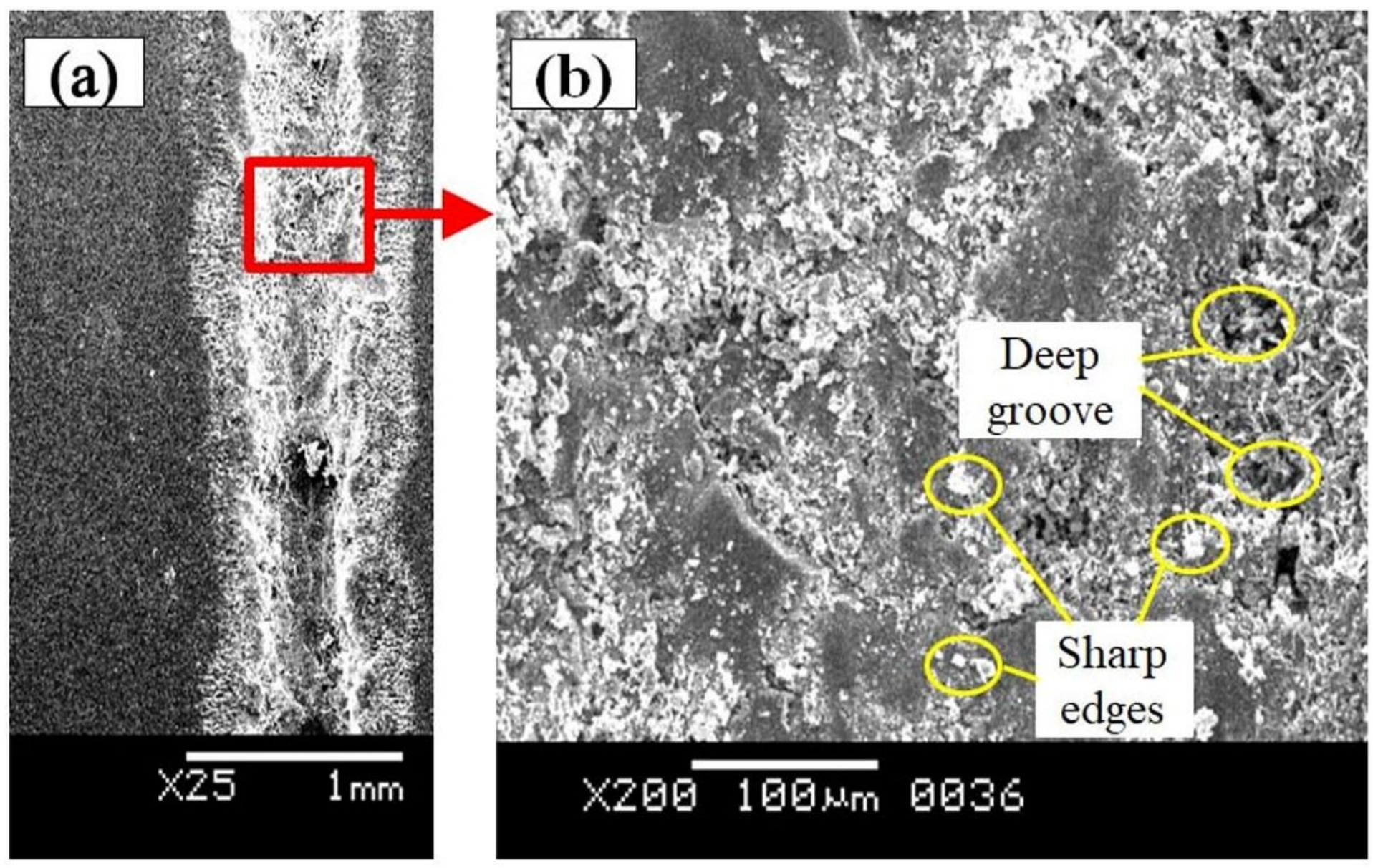

Figure 7

SEM image of the confirmation test (a) machined groove (b) magnified view 